\title{
INFLUENCE OF LIQUID LEVEL ON REATE OF HEAT TRANSFER DURING PROPANE BOILING ON SURFACE WITH CAPILLAR-POROUS STRUCTURE
}

\section{Vitali Litvinenka}

The liquid level above the heat-liberating surface has essential impact on the rate of heat transfer in the field of low thermal loads (by $2 \mathrm{~kW} / \mathrm{m}^{2}$ ), therefore, the study of this phenomenon is a relevant task.

This paper contains the results of experiments for heat transfer during propane boiling in a large volume and on a partially submerged copper tube with the sintered capillary-porous structure. Researches were conducted at saturation temperature $20^{\circ} \mathrm{C}$, what conforms to saturation pressure $\mathrm{p}=8.4$ bars $=8.4 \times 10^{5} \mathrm{~Pa}\left(\mathrm{p}^{*}=\mathrm{p} / \mathrm{p}_{\mathrm{kp}}=\right.$ 0.197), in the area of thermal loads from $0.03 \mathrm{~kW} / \mathrm{m}^{2}$ to $78 \mathrm{~kW} / \mathrm{m}^{2}$. Height of the propane level in relation to the lower generating line of the tube fluctuated from 75 to $0 \mathrm{~mm}$. Experiments showed that liquid level reduction down to $5 \mathrm{~mm}$ above the upper generating line does not considerably influence the rate of heat transfer. With the propane level, commensurate with the diameter of bubbles at departure, heat transfer coefficients were 1.5 times higher than with the same level of thermal loads under conditions of a large volume. Reduction of overheating of the boiling process beginning by $(2.5-3)^{\circ} \mathrm{C}$ was noted as compared with the respective values of heat flux densities during boiling in a big volume. Increase of heat transfer coefficients by 3 times in the area of small thermal loads was fixed at a partially submerged sample. This is explained by various heat exchange mechanisms during steam generation inside the porous layer under conditions of a big volume and during replenishment supply of the heating surface with the liquid phase with the aid of capillary forces.

The further reduction of the liquid level up to the lower generating line of the tube negatively influences the rate of heat transfer at thermal loads above $10 \mathrm{~kW} / \mathrm{m}^{2}$. This is due to the growth of mean overheating of the heat-liberating surface in 
relation to saturation temperature, which is the consequence of worse conditions of liquid delivery to the surface of evaporation with capillary forces.

The obtained results may have important practical value during the design of heat exchangers of the evaporative type, as small sizes and operating efficiency of industrial equipment depend on density of heat flux. 